\title{
Investigation of the rebound number and compressive strength of concrete with quarry dust as fine aggregate
}

\author{
Suppachai Sinthaworn ${ }^{1-2, \text { a }}$ \\ 1 Research Unit in Sustainable Innovation in Civil and Environmental Engineering, Srinakharinwirot University, Thailand \\ 2 Department of Civil Engineering, Faculty of Engineering, Srinakharinwirot University, Thailand
}

\begin{abstract}
This article presents the consideration of relation between compressive strength and rebound number of concrete cooperating with quarry dust as fine aggregate (natural river sand was replaced by quarry dust at the rate of $0 \%, 25 \%, 50 \%, 75 \%$ and $100 \%$ by weight of fine aggregate). The properties of the tested concrete samples are $\mathrm{w} / \mathrm{c}=$ 0.6 , maximum size of coarse aggregate is $20 \mathrm{~mm}$., cement contents are between 308 and $348 \mathrm{~kg} / \mathrm{m}^{3}$, slumps range from 0 to $100 \mathrm{~mm}$., the 28-day compressive strength from 14 to $30 \mathrm{MPa}$. It was found that the rebound number results were affected by quarry dust especially the standard deviator of rebound number. The cube compressive strength at 28 days and the supplementary curve from the instruction manual were discussed. Moreover, the prediction equation is proposed to estimate the compressive strength of concrete cooperating with quarry dust as fine aggregate.
\end{abstract}

\section{Introduction}

Some parts of Thailand experienced a shortage in natural sand for concrete production while crushed sand (quarry waste) is abundant [1]. Therefore, the quarry waste is researched for serving as fine aggregate [2-3]. However, the engineering properties of fine aggregate affects the physical and mechanical properties of concrete such as surface hardness and compressive strength [4].

Non-destructive Testing (NDT) of concrete by hardness method (i.e., Schmidt hammer) has been continuously using since the late 1940s. Schmidt hammer or rebound hammer is widely used in several standards (e.g., ASTM C805, BS 1881: Part 202). In addition, the strength of concrete is governed by both aggregate characteristics and cement paste. A particular aggregate type also results in difference of the correlation between rebound number and compressive strength [4-5]. Then, using NDT for concrete with the new aggregate type should be checked and calibrated.

The objective of this research is to provide the information of the rebound number and related data in order to investigate the compressive strength of concrete with quarry wastes as fine aggregate.

\section{Experimental Procedure}

\subsection{Concrete Sample}

Concrete specimens were made as normal strength concrete. Ordinary Portland cement type I was used while maximum size of coarse aggregate is $20 \mathrm{~mm}$. Coarse aggregate had specific gravities of 2.70 and water absorptions of $0.38 \%$. Two types of fine aggregate are natural river sand and quarry dust. The natural river sand was replaced by quarry dust at the rate of $0 \%, 25 \%, 50 \%$, $75 \%$ and $100 \%$ by weight of fine aggregate. Cement contents are between 308 and $348 \mathrm{~kg} / \mathrm{m}^{3}$. The concrete mixtures are shown in Table 1

After mixing, the initial slump was measured. Then, the concrete specimens $(15 \times 15 \times 15 \mathrm{~cm})$ were casted. After casting for 24 hours, all concrete specimens were remolded and cured in water at room temperature. Compressive strength of specimens were tested at the ages of 7 and 28 days.

In summary, the properties of the concrete samples are $\mathrm{w} / \mathrm{c}=0.6$, slumps range from 0 to $100 \mathrm{~mm}$. the 28 day compressive strength from 14 to $30 \mathrm{MPa}$.

\subsection{Rebound hammer}

This study used the rebound hammer (mechanical concrete test hammer, MATTEST brand) as shown in Fig.1. The interpretative curve as in the instruction manual is also shown in Fig.1.

Before destructive test (compressive strength test by universal testing machine), concrete specimens were investigated by the rebound hammer to obtain the rebound number from 10 locations on left and right face of the cube specimen as shown in Fig. 2.

\footnotetext{
a Corresponding author: suppachai@g.swu.ac.th
} 
Table 1. Mixture proportion of concrete samples.

\begin{tabular}{|c|c|c|c|c|c|}
\hline \multirow{2}{*}{$\begin{array}{c}\text { Mix. } \\
\text { ID }\end{array}$} & \multicolumn{5}{|c|}{ Weight per cubic meter [kg] } \\
\cline { 2 - 6 } & Cement & Water & $\begin{array}{l}\text { Coarse } \\
\text { Aggregate }\end{array}$ & $\begin{array}{c}\text { River } \\
\text { Sand }\end{array}$ & $\begin{array}{c}\text { Quarry } \\
\text { Dust }\end{array}$ \\
\hline W0 & 312 & 187 & 1,247 & 624 & 0 \\
\hline W25 & 312 & 187 & 1,247 & 468 & 156 \\
\hline W50 & 312 & 187 & 1,247 & 312 & 312 \\
\hline W75 & 312 & 187 & 1,247 & 156 & 468 \\
\hline W100 & 312 & 187 & 1,247 & 0 & 624 \\
\hline V0 & 348 & 209 & 1,197 & 583 & 0 \\
\hline V25 & 348 & 209 & 1,197 & 438 & 146 \\
\hline V50 & 348 & 209 & 1,197 & 292 & 292 \\
\hline V75 & 348 & 209 & 1,197 & 146 & 438 \\
\hline V100 & 348 & 209 & 1,197 & 0 & 583 \\
\hline A0 & 308 & 179 & 1,009 & 874 & 0 \\
\hline A25 & 308 & 179 & 1,009 & 656 & 219 \\
\hline A50 & 308 & 179 & 1,009 & 437 & 437 \\
\hline A75 & 308 & 179 & 1,009 & 219 & 656 \\
\hline A100 & 308 & 179 & 1,009 & 0 & 874 \\
\hline
\end{tabular}
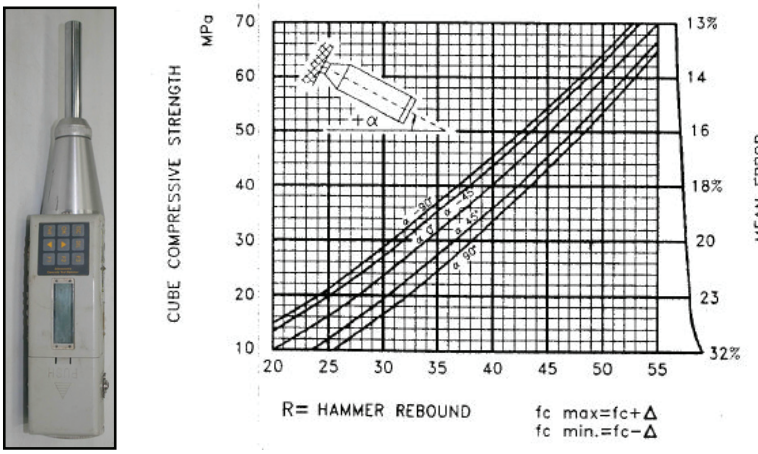

Fig. 1. The rebound hammer and the interpretative curve (from user manual [6]).
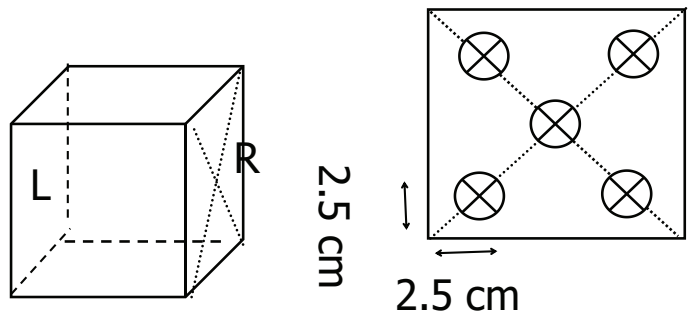

Fig. 2. The tested locations of rebound number on the cube specimen.

\section{Results and Discussions}

\subsection{Median and Average of Rebound Numbers}

From the manual, the rebound number can be considered reliable if any readings are not further from the average than the amount specified below:
Rebound Number $(\mathrm{H})$
$\begin{array}{lll}15 & 30 & 45\end{array}$
Discard reading $+/$ -
$2.5 \quad 3.0 \quad 3.5$

The average rebound number should be obtained from the average of the 10 best readings.

However, to discard some readings in practical might results in a biased data because of human error. On the other hand, to discard some readings which are different from average could effect on the final average value of rebound number. Therefore, using of the average value without discard some reading could be more reasonable.

The Median is the "middle" of a sorted list of numbers. The median is quite similar idea with discard the numbers that above and below averages. Fig. 3a shows the relationship between median and average of 10 readings of rebound number. This figure reveals that the average values of 10 readings of rebound number are slightly higher than that of median value. Therefore, to interpret the result by median or average value might differ approximately 2 units of rebound number.

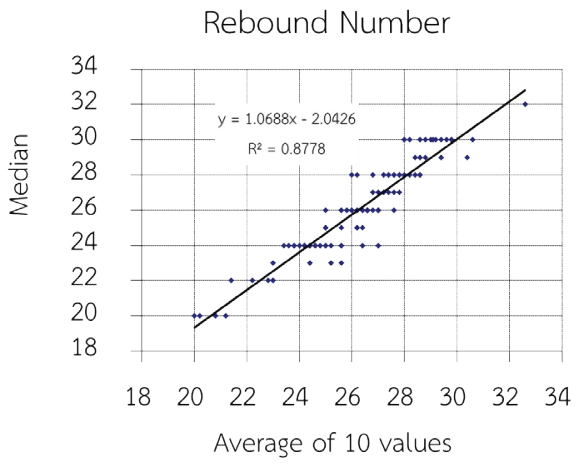

(a)

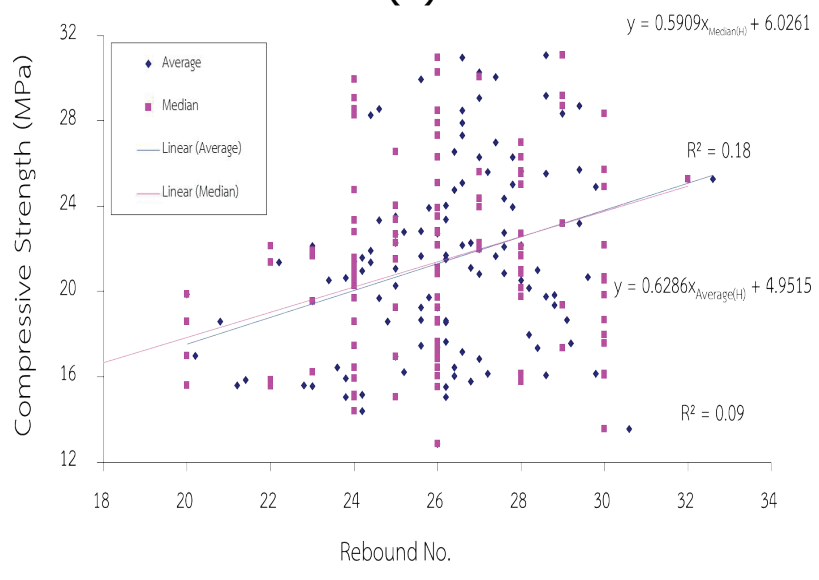

(b)

Fig. 3. (a) Relationship between median and average of rebound number. (b) Compressive strength versus rebound number of all specimens. 


\subsection{Relationship between Compressive Strength and Rebound Number}

The compressive strength of all concrete samplings versus the rebound number are illustrated in Fig. $3 b$. The two linear regressions of the rebound number (average and median) and compressive strength show quite small $\mathrm{R}^{2}$ value. However, the regression from median value of the obtained rebound number seems more accurate value to predict the cube compressive strength than using the regression from average rebound number.

\subsection{Comparative Prediction of Compressive Strength between from the Manual and the Regression}

Fig.4 demonstrations the prediction of compressive strength by rebound number from the manual and the linear regression of the relationship between compressive strength and rebound number. The linear regression (blue line) shows approximately $\pm 20 \%$ fluctuation from the mean compressive strength while the suggestion value and range from the manual (green line) matches only a small regions of the data. Moreover, it should be noted that compressive strength range from 12 to $32 \mathrm{MPa}$ could be obtained from a narrow range of rebound number from 20 to 32 (12 units).

\subsection{The Prediction Equation}

Fig.5 displays the plots of the compressive strength of concrete versus the obtained rebound number. Those concretes were separated into three types of fine aggregate which are 1) river sand \{red triangle, normal\}, 2) quarry dust \{dash line, $Q\}$, and 3 ) mixed of river sand and quarry dust. Mostly results are in the prediction band of the regression line (prediction value $\pm 20 \%$ ). However, some results locate above and below the prediction area. It could not find an evidential on the effect of fine aggregates type from Fig.5. However, the proposed equation for concrete with quarry dust as fine aggregate is mentioned in $\mathrm{Eq} 1$.

$$
f^{\prime} c=0.5909 H+6.0261
$$

where $H$ is the median of the obtained rebound number. $f^{\prime} c$ is the cube compressive strength of concrete (MPa).

\section{Conclusions}

Based on the results of this study, the following conclusions could be drawn:

- The average and median value of the obtained rebound number might not equal, and the median of the obtained rebound number seems more reasonable value to predict the cube compressive strength than using average value of the obtained rebound number.

- The proposed equation for concrete with quarry dust as fine aggregate is mentioned as using the median of the obtained rebound number. However, the predicted compressive strength obtains from a narrow range of the rebound number (only 12 units). It is possible to achieve a new relationship between rebound number and compressive strength by the experiment for the new case to get the better prediction result.

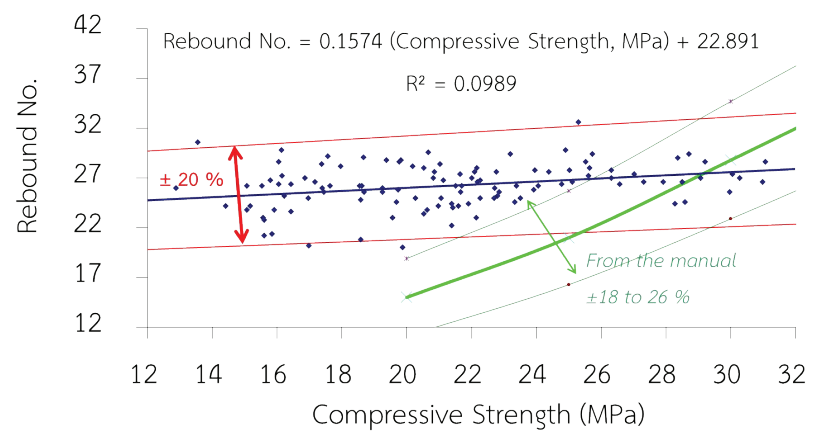

Fig. 4. Comparative prediction of compressive strength from the manual and a regression.

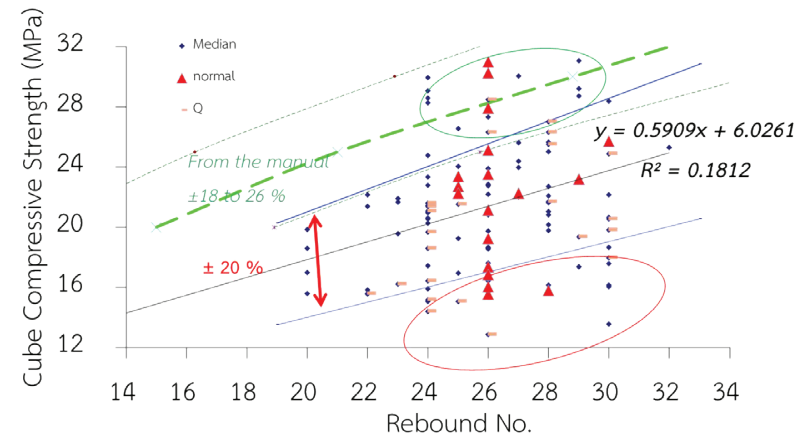

Fig. 5. The plots of compressive strength versus rebound number of the different mixtures.

\section{Acknowledgements}

This work was financially supported by Faculty of Engineering, Srinakharinwirot University under contract No. 147/2552 and the authors gratefully acknowledge the financial support to present this work in the conference from Strategic Wisdom and Research Institute, Srinakharinwirot University.

\section{References}

1. S. Sinthaworn, T. Koseekageepat, O. Saengmanee, Advanced Materials Research 974, 350-353 (2014),

2. S. Sinthaworn, W. Teerajetgul and A. Sirivachiraporn, Advanced Materials Research 875877, 619-623 (2014)

3. S. Sinthaworn, Materials Science Forum, 886, 159163 (2017)

4. J.H. Bungey and S.G. Millard, "Testing of Concrete in Structures", Third edition, Blackie Academic \& Professional, Chapman \& Hall, 1996.

5. S. Sinthaworn. 2010." Assessment of Strength of Concrete by Rebound Hammer", SWU Engineering Journal 5(2), 41-49 (2010). (in Thai).

6. MATTEST, Mechanical Concrete Test Hammer, Manual User Guide, www.matest.com, Italy. 